\title{
Estimation of cables' tension of cable-stayed footbridge using measured natural frequencies
}

\author{
Przemysław Jakiel ${ }^{1 *}$ and Zbigniew Mańko ${ }^{2}$ \\ ${ }^{1}$ Opole University of Technology, Katowicka Street, No 48, 45-061 Opole, Poland \\ ${ }^{2}$ International University of Logistic and Transport, Soltysowicka, No. 19B, 51-168 Wrocław, Poland
}

\begin{abstract}
This paper presents analysis of cables' tension of steel cablestayed footbridge using their field-test natural frequencies. A vibration method is usually used for the measured cable tension during the construction of cable systems stiffened with inclined cables. Practical formulas for the vibration method applied herein, mainly based on cablesag and vertical angle effects (a survey measurement), have been verified on the one-tower steel cable-stayed bridge. The bridge is situated in Sieradz (Poland) and it was the structure with the longest span concerning all the cable-stayed bridges in Poland until 1999. The obtained cable axial forces for estimated natural frequencies of low- and high-order modes are verified using FEM models. The final conclusions drawn on the basis of conducted studies can be useful for technical diagnosis, monitoring programs and repair works of similar class of cable-stayed bridges.
\end{abstract}

\section{Introduction}

A knowledge of cable tensions is very important concerning suitable geometry of the cablestayed bridges and it allows to create their detailed calculation models [1]. The cable axial force can be estimated by the method using measured natural frequencies, which depend not only on axial force but on flexural stiffnes, cable sag and inclination of the cable chord as well. According horizontal cable configuration with relatively small sag the cable tension $F$ we can obtain from well known formula $F=A \rho L^{2} f^{2} / g$ ( $A$ - cross section area, $\rho$ - material density, $L$ - length, $f$ - natural frequency, $g$ - gravitational acceleration) applicable for firstorder mode only, but the result may be burden with error concerning longer tendons [2].

In this paper, verification of the accurate method which allows to estimate the cable axial force using measured its natural frequencies, taking into consideration aforementioned material and geometrical parameters is presented.

Considering the very slender tendons, i.e. those that are the structural members in the cable-stayed bridges for instance is difficult to excite the cable artificially to first or secondorder mode oscillation. In this case, one should use the results obtained from stationary vibrations, in which modes of high order are usually dominant.

${ }^{*}$ Corresponding author: p.jakiel@po.opole.pl 
So called vibration method proposed by Zui, Shinke and Namita [3] is herein briefly described with unification of practical formulas, and applied to the results of natural frequencies obtained from the measurement conducted on a cable-stayed pedestrian bridge in Sieradz (Poland) and the accuracy is confirmed using FEM models [4].

\section{Short description of footbridge structure}

The cable-stayed footbridge in Sieradz was built in 1978 for pedestrian traffic and emergency vehicle, e.g. fire engine. The total length of this bridge is $142 \mathrm{~m}$ with effective spans equal to $9.12+75.88+3 \times 19.00 \mathrm{~m}$, respectively. The steel superstructure consists of one portal tower, consisted of closed, rectangular cross-section, cable system arranged in harp layout and an orthotropic plate deck (Fig. 1a). Total height of the tower transversally braced in the locations of cable joints is $43.48 \mathrm{~m}$. The cables are fixed to the tower and anchored to the deck. The tower is rigidly fixed to the main girders and supported by the steel hinge bearings situated on a pier P2 (Fig. 1b).
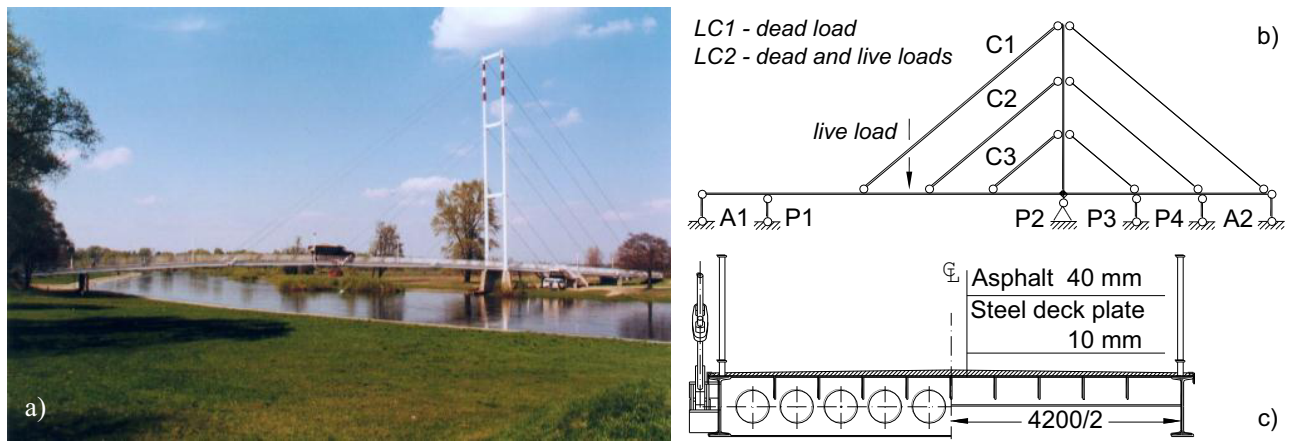

Fig. 1. Sieradz cable-stayed footbridge considered in this investigation: (a) side view, (b) calculation scheme and (c) cross-sections.

The steel deck structure, which is $4.10 \mathrm{~m}$ wide, is composed of two I-beams $550 \mathrm{~mm}$ main girders, the openwork and plain girder double-tee cross-beams of $525 \mathrm{~mm}$ and 250 $\mathrm{mm}$ high respectively (Fig. 1c). The cross-beams are alternately spaced: the major ones $7.40 \mathrm{~m}$ and the minor ones $1.90 \mathrm{~m}$. The steel plate orthotropic deck consists of $10 \mathrm{~mm}$ thick plate and the longitudinal stiffening ribs $(12 \times 200)$. The plate deck is directly topped with a $50 \mathrm{~mm}$ thick layer of asphalt [5].

The cables are made of helical wires closed by the z-profile wires in the cross-section in diameter of $48 \mathrm{~mm}$. A peculiar feature of this bridge are the rocker bearings at each support except the pier P2, which enable limited longitudinal and vertical displacements of the spans at their supports.

\section{Vibration method's formula}

A simplified algorithm of presented herein the vibration method is used for free-oscilation frequencies of the cable with its span length denoted as $L$, sag $d$ and angle of cable inclination $\alpha$ (Fig. 2a) [3].

Introducing a dimensionless parameter $\chi(1)$ :

$$
\chi=L \times \sqrt{F / E J},
$$


where $E J$ is flexural rigidity of cable, the range of application of the method is specified as any region of $\chi$, so far as first or second-order vibration' modes obtained on the basis of the field measurement. Moreover, Shimada, using high natural frequency, discovered a formula useful for very slender cables $(\chi \geq 200)$, which often appear in the cable-stayed bridges [6].

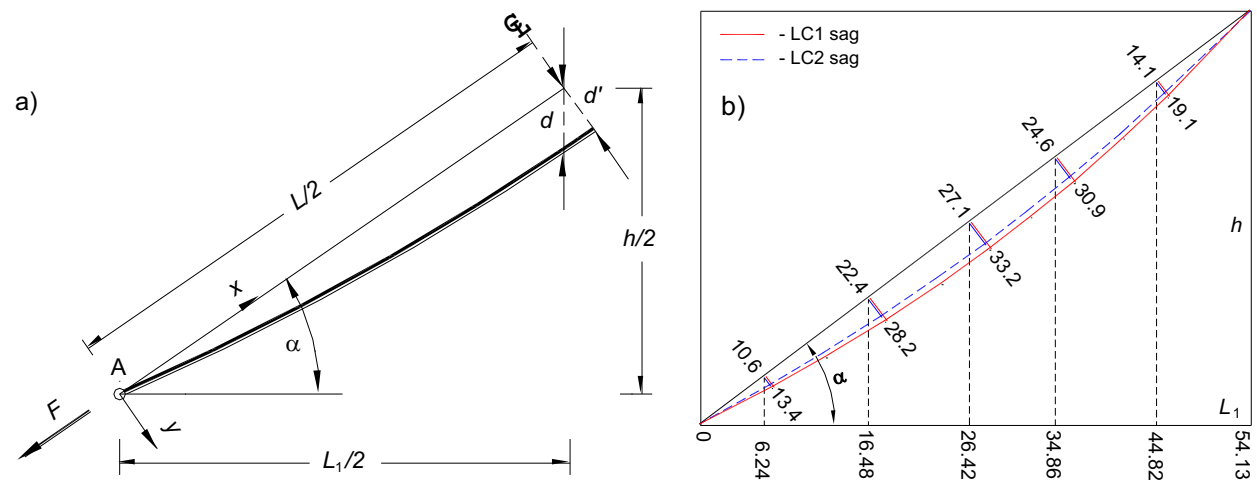

Fig. 2. Scheme of inclined cable (a) and analyzed bridge $\mathrm{C} 1$ cable with the sags under load case 1 and load case 2 (b).

The following assumptions have been made in the analysis:

- a second-order parabola is the geometric shape of the cable,

- the sag-to-span ratio is sufficiently small $\left(e=d / L_{1}<<1\right)$,

- the cable vibrates in $x-y$ plane only and its motion in the $x$-direction is neglibly small.

The method states the basic equation of motion in the $y$-direction of a beam with axial tension $F$ as follows [3]:

$$
E J \frac{\partial^{4} v(x, t)}{\partial x^{4}}-F \frac{\partial^{2} v(x, t)}{\partial x^{2}}+\frac{q_{c}}{g} \frac{\partial^{2} v(x, t)}{\partial t^{2}}=0,
$$

where $v(x, t)$ - dynamic deflection in the $y$-direction and $q_{\mathrm{c}}$ - weight of cable per unit length.

By means of variable separation and after transformation of above equation a transcendental equation can be obtained and thus, assuming the dynamic characteristic of a cable is similar to that of a string, i.e. parameter $\chi$ is large, a nondimensional parameter $\eta_{n}$ was introduced (3):

$$
\eta_{n}=\frac{f_{\mathrm{c}}}{f_{n}^{\mathrm{s}}}
$$

where $f_{\mathrm{c}}=\omega / 2 \pi$, and $f_{n}^{\mathrm{s}}$ is theoretical value of the $n$-th order natural frequency of a string expressed in the form [3]:

$$
f_{n}^{s}=\frac{n}{2 L} \sqrt{\frac{F g}{q_{c}}}
$$

By substituting obtained values into equation of free vibration of the string clamped at both ends [3], after transformation we can obtain also transcendental equation and the solution $\eta_{n}$ can be obtained by one of an iterative methods.

In a case when a cable has relatively large sag, there are introduced an approximate solutions for the first-order mode in a form: 


$$
f_{n}^{\mathrm{c}}=\frac{\beta}{\pi} \sqrt{\frac{g}{8 d}},
$$

where $\beta=n \pi(n=1,2, \ldots)$ for unsymmetric mode, and $\beta=\Lambda_{0}$ for symmetric one [3]:

$$
\frac{\beta-\operatorname{tg} \beta}{\beta^{3}}=\Lambda_{0} \quad \text { and } \quad \Lambda_{0}=\frac{q_{\mathrm{c}} L}{128 E A e^{3} \cos ^{5} \alpha}
$$

The effect of a cable elongation and/or contraction is not concerned in above equations, except included cable shape changes, what appears in solutions as coincidence with those of a string for unsymmetric modes. Finally, the effect of extension and/or contraction of a cable is significant and derivative cable forces $F$ due to vibrations cannot be neglected for symmetric modes [3]. This natural frequency can be determined by parameter $\Lambda_{0}(6)$, as a function of length, sag, weight, flexural rigidity and inclination angle of cable.

The range of applicability of considered statements is precised by parameter $\Lambda^{\prime}$ and $\chi$, which are both introduced in a new parameter $\Lambda$ in the form:

$$
\Lambda=\Lambda^{\prime} \frac{0,31 \chi+0,5}{0,31 \chi-0,5} \text { where } \Lambda^{\prime}=\sqrt{\Lambda_{0}} .
$$

In a case of $\Lambda<3$, two values of cable force $F$ give the same first-order symmetric natural frequency. We can observe that cable force is very sensitive to the change of firstorder natural frequency in the area of large values of cable sag and its derivative axial force and from this reason even small measurement error of free-vibration frequency may generate a large error of cable force [3]. Thus, it is desirable to use second-order natural frequency (or higher-order one) for the measurement of cable force with insignificant error, i.e. when effect of cable sag and derivative of cable force is relatively small.

Applicable region of the formula depends on parameter $\chi$, which is influenced by cable sag in relation with the natural modes $n$, what is specified as $\Lambda \geq 3$ (for cable with sufficiently small sag, $n=1$ ) and $\Lambda<3$ (for cable with relatively large sag, $n=2$ ) and also

\begin{tabular}{|c|c|c|c|c|c|c|}
\hline \multirow{2}{*}{ Mode } & \multirow{2}{*}{ Equations } & \multicolumn{2}{|c|}{ Parameters } & \multicolumn{3}{|c|}{ Coefficients } \\
\hline & & $\chi$ & $\Lambda$ & A & $\mathrm{B}$ & $\mathrm{C}$ \\
\hline \multirow{3}{*}{1} & \multirow{3}{*}{$F=\frac{4 q_{\mathrm{c}}}{\mathrm{g}}\left(f_{1} L\right)^{2}\left[\mathrm{~A}+\mathrm{B} \frac{\Psi}{f_{1}}-\mathrm{C}\left(\frac{\Psi}{f_{1}}\right)^{2}\right]$} & $0-6$ & \multirow{3}{*}{$\geq 3$} & 0.828 & 0 & 10.65 \\
\hline & & $6-17$ & & 0.865 & 0 & 11.60 \\
\hline & & $\left.\geq 17^{*}\right)$ & & 1 & -2.20 & 0.55 \\
\hline \multirow{3}{*}{2} & \multirow{3}{*}{$F=\frac{q_{\mathrm{c}}}{\mathrm{g}}\left(f_{2} L\right)^{2}\left[\mathrm{~A}+\mathrm{B} \frac{\Psi}{f_{2}}-\mathrm{C}\left(\frac{\Psi}{f_{2}}\right)^{2}\right]$} & $0-17$ & \multirow{3}{*}{$<3$} & 0.882 & 0 & 85.00 \\
\hline & & $17-60$ & & 1.030 & -6.33 & 1.58 \\
\hline & & $\left.\geq 60^{*}\right)$ & & 1 & -4.40 & 1.10 \\
\hline$n>2$ & $\left.F=\frac{4 q_{\mathrm{c}}}{n^{2} \mathrm{~g}}\left(f_{n} L\right)^{2}\left(1-2,20 \frac{n \Psi}{f_{n}}\right)^{*}\right)$ & $\geq 200$ & - & - & - & - \\
\hline $\begin{array}{l}\Psi= \\
\left.{ }^{*}\right) \\
\text { the }\end{array}$ & $\begin{array}{l}\frac{E J \mathrm{~g}}{q_{\mathrm{c}} L^{4}} \\
\text { ormulas applied herein }\end{array}$ & & & & & \\
\hline
\end{tabular}
as $\chi \geq 200$ for very long cables, $n \geq 2$ (Table 1) [3].

Table 1. Basic formulas allowing to calculate axial force in a cable. 


\section{Tension of cables using field test free-vibration measurement}

In order to determine axial forces in the selected bridge cables ( 1 1 - C3) natural frequencies obtained from the measurements were used [4], [5]. Selected investigated results of $\mathrm{C} 3$ cable's natural frequencies are illustrated in Fig. 3.

What is indispensable for the application of the given method is knowledge of the cable sag, which - although does not directly impact the axial force being calculated - is used indirectly for classifying it in the relation of the $\Lambda$ factor: sag size - cable chord length. It was justified in the paper [4] that the lack of measurement results for the sag of cables shorter than C1 (e.g. C2 and C3) is of no significant influence on the error value.

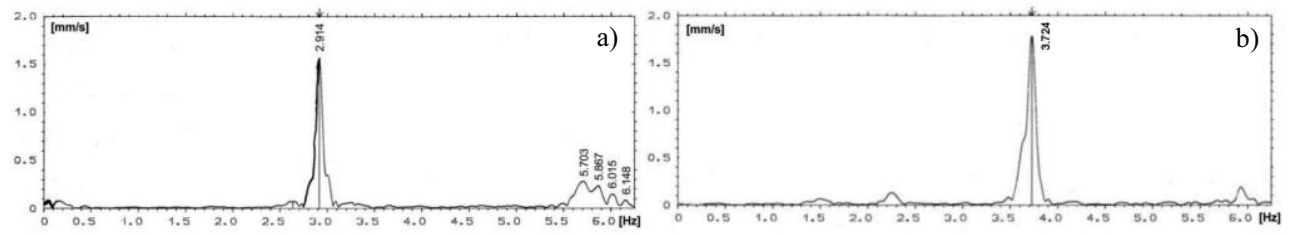

Fig. 3. Spectrum of manually excited first-order free-vibrations of C3 cable under (a) dead load (LC1) and (b) live load (LC2).

The following were assumed for the analyzed slender cables: experimentally determined value of Young's modulus $E_{\mathrm{c}}=172 \mathrm{GPa}$, a unit dead load $q_{\mathrm{c}}=134.8 \mathrm{~N} / \mathrm{m}$, a cross-section area $A=1.635 \times 10^{-3} \mathrm{~m}^{2}$, a moment of inertia $J=2.606 \times 10^{-7} \mathrm{~m}^{4}$ and $\mathrm{g}=9.81 \mathrm{~m} / \mathrm{s}^{2}$ [4].

Formula (1) indicates the need to apply a preliminary estimated value (e.g. a design value) of the $F_{\mathrm{o}}$ - axial tensile force in the cable for further calculations, which leads to the determination of the $\chi$ parameter. It was justified that high accuracy while determining $F_{\mathrm{o}}$ is of no particular significance for the final result and thus the results obtained from the preliminary FEM analysis of the bridge model were applied for further calculations of cable tensions. In order to determine the $F_{1}$ preliminary cables' tensions, it was assumed that their effort balances the bridge spans' dead load (LC1), whereas in order to determine the design value of the $F_{2}$ axial force (LC2), an additional live load provided by a vehicle (weighing $250.6 \mathrm{kN}$ ) in the middle of the longest bridge span was applied (Fig. 1a, b) [4].

While the difference between the assumed $F_{1-\mathrm{o}}$ cable tension and the $F_{1}$ real value might be quite large, the difference in cable tensions under load case 1 and load case 2, determined with the use of the suggested method and FEM, should not be significant.

Parameters used in the calculations of values of the $F$ axial forces in $\mathrm{C} 1-\mathrm{C} 3$ cables under dead load only (LC1), as well as under live load has been applied (LC2), were compiled in Table 2, where detailed $\mathrm{C} 1$ cable sags are showed on Figure $2 \mathrm{~b}$.

Table 2. Assumed values and parameters necessary for the determination of the $F$ axial force in the selected cables of the cable-stayed bridge under analysis.

\begin{tabular}{|c|c|c|c|c|c|c|c|c|c|c|}
\hline \multirow{3}{*}{$\frac{\frac{0}{0}}{\frac{\pi}{\pi}}$} & \multirow{2}{*}{$F_{0}$} & \multirow{2}{*}{$L$} & \multirow{2}{*}{$\chi$} & \multirow{2}{*}{$d$} & \multirow{2}{*}{$\alpha$} & \multirow{2}{*}{$e$} & \multicolumn{2}{|c|}{ Parameters } & \multirow{2}{*}{$f_{n}$} & \multirow{2}{*}{$F$} \\
\hline & & & & & & & $\Lambda$ & $\Psi$ & & \\
\hline & $(\mathrm{kN})$ & (m) & - & (m) & $\left({ }^{\circ}, ”\right)$ & $\times 10^{-3}$ & - & $\times 10^{-3}\left(\mathrm{~s}^{-1}\right)$ & $(\mathrm{Hz})$ & $(\mathrm{kN})$ \\
\hline \multirow{2}{*}{$\mathrm{C} 1$} & $\begin{array}{r}84.70 \\
186.34\end{array}$ & 67.822 & $\begin{array}{r}93 \\
138\end{array}$ & 0.416 & 370240 & 7.685 & $\begin{array}{l}1.36 \\
1.35\end{array}$ & 12.417 & $1.72\left(f_{2}\right)$ & 180.612 \\
\hline & $\begin{array}{l}125.00 \\
228.19\end{array}$ & 67.831 & $\begin{array}{l}113 \\
153\end{array}$ & 0.340 & 370424 & 6.282 & $\begin{array}{l}1.83 \\
1.82\end{array}$ & 12.413 & $2.80\left(f_{3}\right)$ & 213.233 \\
\hline \multirow{2}{*}{$\mathrm{C} 2$} & 145.90 & \multirow{2}{*}{46.140} & 83 & 0.193 & \multirow{2}{*}{362733} & 5.201 & 1.99 & \multirow{2}{*}{26.828} & $3.21\left(f_{2}\right)$ & 290.322 \\
\hline & 297.00 & & 118 & 0.157 & & 4.231 & 2.68 & & $3.90\left(f_{2}\right)$ & 431.004 \\
\hline \multirow{2}{*}{$\mathrm{C} 3$} & 142.90 & \multirow{2}{*}{22.667} & 41 & 0.047 & \multirow{2}{*}{364302} & 2.587 & 4.16 & \multirow{2}{*}{111.161} & $2.91\left(f_{1}\right)$ & 219.482 \\
\hline & 303.10 & & 59 & 0.038 & & 2.091 & 5.59 & & $3.72\left(f_{1}\right)$ & 365.120 \\
\hline
\end{tabular}


Additional calculations were carried out for the longest $\mathrm{C} 1$ cable, taking into account the initially determined (design) value of the axial force, which amounted to $84.7 \mathrm{kN}$ for LC1 and, with the use of its value determined on the basis of considerations concerning the changes of geometry of cable (sag), amounting to $186.3 \mathrm{kN}$ for the actual load condition [4]. What can be noticed is the fact that although the calculation axial force $F_{\mathrm{o}}$ has more than doubled it is of no substantial influence on the final value which in both cases amounts to $F_{1(\mathrm{C} 1)}=180.6 \mathrm{kN}$ for load case 1 and $F_{2(\mathrm{C} 1)}=213.2 \mathrm{kN}$ for load case 2 . The only values that have changed are the ones of $\chi \mathrm{i} \Lambda$ parameters which - being of the utmost importance in the phase of selecting a proper algorithm for the $\delta$ relation - did not have an impact on the change of classification of a given element (e.g. for cables with a relatively small sag that is at $\Lambda>3$, Table 1 ).

\section{Tension of cables using MES model}

On the basis of our own experience included in the paper [4] it was assumed that, with the knowledge of specific geometrical characteristics of a bridge cable, it is possible to apply the FEM model of a single (isolated) cable without the risk of making a serious mistake, as well as to determine the axial force on this basis.

Calculations under the static loads were made for the $\mathrm{C} 1$ cable discretized with 24 twonode linear elements (of the cable type) in the $2 D$ set for the geometrical and material data given in item 4 . Due to the strong nonlinearity of such an element, calculations were carried out taking into consideration geometrical nonlinearity with the use of Newton-Raphson iterations (Fig. 4a).

The analysis was carried out in three stages assuming a single span cable clamped at both ends and the cable axial force almost equal to zero $(F=1 \mathrm{~N} \approx 0 \mathrm{~N})$ in the first one, with one roller support and a maximum expected vertical displacement (sag) in the middle of the span of a macroelement $y_{\max }=332.3 \times 10^{-3} \mathrm{~m}$ (LC1) in the second stage, and finally $y_{\max }=271.2 \times 10^{-3} \mathrm{~m}(\mathrm{LC} 2)$ in the third one (Fig. $\left.4 \mathrm{~b}, \mathrm{c}\right)[4]$.

In order to establish the approximate values of cable tensile forces for the known $d$ ' sags, a load bigger than the expected one was applied in the initial phase, while the relation of displacement - load $(y-\lambda)$ parameters was being controlled. It was found that the following tensile forces of a cable refer to its specific $d$ ' values: $F_{1}=182.75 \mathrm{kN}$ and $F_{2}=223.95 \mathrm{kN}$.
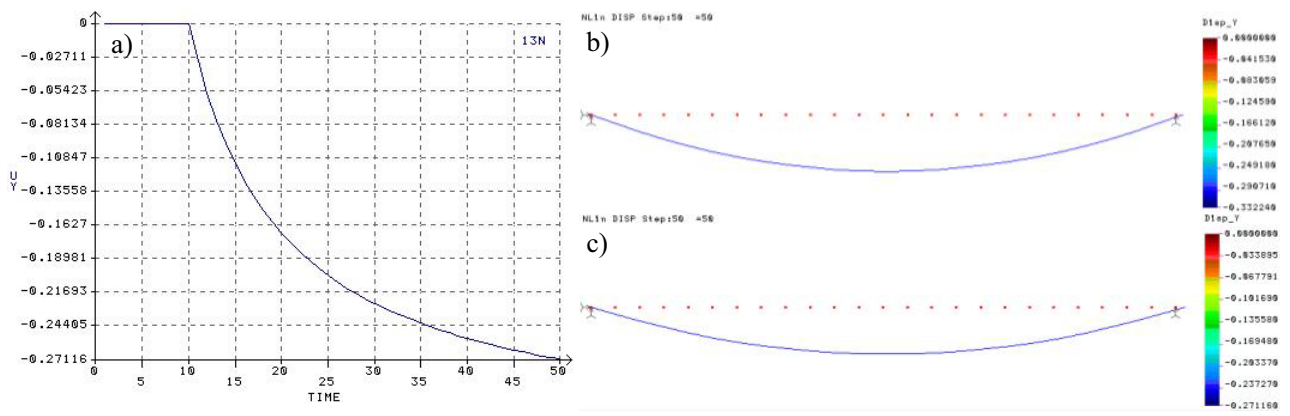

Fig. 4. Relation between vertical displacement of the central nod of $\mathrm{C} 1$ cable finite model (FEM1) and live load, LC2 (a); deflection of discrete the same cable model under the cable dead load and the $F_{1}$ axial force, LC1 (b) and the $F_{2}$ axial force, LC2 (c), scale 20:1. 


\section{Results and analysis}

Relationships between natural frequencies in the function of the obtained axial forces in $\mathrm{C} 1$ - C3 cables under two load cases were presented in Figure 5.

The analysis of the obtained results allows to claim that the increase in the $F$ force, similar for each of the cables, in case of $\mathrm{C} 1$ occurred for the smallest region of natural frequencies due to the fact that the third mode vibration was assumed for consideration.

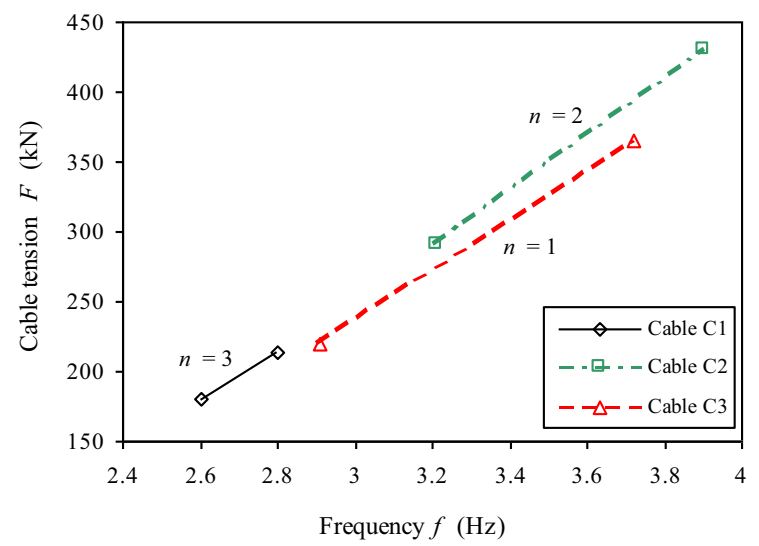

Fig. 5. Relation between tension $F$ and natural frequency $f($ for $n=3,2$ i 1 ) for the bridge C1-C3 cables.

On the basis of FEM calculations (the course of $y$ vertical displacements), it was noted that the cable model displays a strong nonlinearity [2]. Comparing the values of the axial tensile forces in the $\mathrm{C} 1$ cable obtained from the FEM (model of an isolated cable), it was concluded that they were in agreement with the results obtained pursuant to the considered method determining the cable axial force by measuring its natural frequency (VM) with the difference not exceeding $5 \%$ (Table 3). On the other hand, if we take into account the increase in the axial force $\Delta F_{\mathrm{C} 1}=F_{2}-F_{1}$ in the same cable, the difference is slightly bigger and amounts to $20.8 \%$.

Table 3. Comparison of the axial forces in $\mathrm{C} 1-\mathrm{C} 3$ cables resulting from vibration method and FEM calculations.

\begin{tabular}{|c|c|c|c|c|c|}
\hline \multirow{2}{*}{$\begin{array}{c}\text { Cable } \\
\text { No }\end{array}$} & \multirow{2}{*}{ Load case } & \multicolumn{3}{|c|}{ Axial force $(\mathrm{kN})$} & \multirow{2}{*}{ VM / FEM (\%) } \\
\cline { 2 - 6 } & & VM & FEM1 & FEM2 & \\
\hline \multirow{3}{*}{$\mathrm{C} 1$} & $F_{1}(\mathrm{LC} 1)$ & 180.61 & 182.75 & - & 98.8 \\
\cline { 2 - 6 } & $F_{2}(\mathrm{LC} 2)$ & 213.23 & 223.95 & - & 95.2 \\
\cline { 2 - 6 } & $\Delta F_{\mathrm{C} 1}=F_{2}-F_{1}$ & 32.62 & 41.20 & 36.07 & $79.2 / 90.5$ \\
\hline $\mathrm{C} 2$ & $\Delta F_{\mathrm{C} 2}$ & 140.68 & - & 137.95 & 102.4 \\
\hline $\mathrm{C} 3$ & $\Delta F_{\mathrm{C} 3}$ & 145.64 & - & 141.32 & 103.1 \\
\hline
\end{tabular}

Certain discrepancies in the obtained results might be due to, among others, the fact that two distinct initial tensions of a given element were assumed, as well as the fact that cable sag was not included in the calculations according to the second order theory (FEM) in the given comparative example for the calculation full bridge model [4]. 


\section{Final conclusions}

Verification of the method allowing to assess the tension level of cables in cable-stayed bridges taking into account the geometric and material characteristics of these first ones was presented in the paper. The following conclusions have been formulated on the basis of our own observations and after the results obtained with the use of the FEM have been verified:

- The suggested method allows to determine with quite an ease the current condition of axial forces in cables, however, what is indispensable to do so is a precise measurement of their actual geometry and at least estimated identification of their initial axial tension. Also, a change of the cross-section of a cable due to corrosion or an additional load of the anticorrosion protection might be of certain influence here.

- Particular attention should be paid to the manner of inducing cable vibrations, i.e. solely in the plane of its sag, as well as to the register of dynamic parameters and interpretation of the vibration spectrum. The aforementioned is due to the sensitivity of this method to the measurement error, in particular for lower natural frequencies.

- The obtained results of axial forces in the selected cables of the bridge point to certain discrepancies between both applied methods, which might be caused by the above named reasons.

- The presented algorithm along with the analysis methodology of the isolated cable element (FEM) taking into consideration geometrical nonlinearity allows to prospectively apply them in the course of research and calculation analysis not only of cable-stayed bridges but also other systems in which cables constitute bearing structural members.

- The need to verify the suggested algorithm within the scope of determining the changes of cable tension in laboratory conditions is also pointed out. This shall allow to, among others, determine the influence of damping on the obtained cable tensions.

\section{References}

1. R. Walther, B. Houriet, W. Isler, P. Moia, Cable stayed bridges (London, Thomas Telford Ltd, 1988)

2. J. Hajduk, J. Osiecki, Cable structures. Theory and calculations (WNT, Warsaw, 1970) (in Polish)

3. H. Zui, T. Shinke, Y. Namita, Practical formulas for estimation of cable tension by vibration method. J. Str. Eng., ASCE, 122, 6, 651-656 (1996)

4. P. Jakiel, Evaluation of nonlinear effects in steel cable-stayed bridges. Ph.D. Thesis (Wrocław University of Technology, Wrocław 2005) (In Polish)

5. P. Jakiel, Z. Mańko, Dynamic response of steel cable-stayed bridge in Sieradz. XLVI Scientific Conf., Wrocław-Krynica, 4, 34-40 (2000)

6. T. Shimada, Estimating method of cable tension from natural frequency of high mode. Proc. of JSCE, 501/1-29, 163-171 (1994) 